\title{
Cost-effectiveness of treprostinil versus epoprostenol in patients with pulmonary arterial hypertension: A Canadian analysis
}

\author{
Thomas R Einarson $\mathrm{PhD}^{1,2}$, John T Granton MD FRCS ${ }^{3}$, Colin Vicente BSc ${ }^{2}$, John H Walker PhD ${ }^{2,4}$, \\ Greg Engel $\mathrm{BSc}^{5}$, Michael Iskedjian BPharm MSc${ }^{2}$
}

TR Einarson, JT Granton, C Vicente, JH Walker, G Engel, M Iskedjian. Cost-effectiveness of treprostinil versus epoprostenol in patients with pulmonary arterial hypertension: A Canadian analysis. Can Respir J 2005;12(8):419-425.

BACKGROUND: Pulmonary arterial hypertension (PAH) is associated with substantial morbidity and mortality, exerting a tremendous health and economic impact on patients. In the present study, an economic evaluation of patients with PAH treated with either treprostinil or epoprostenol was performed.

METHODS: A cost-minimization analysis (a cost-effectiveness subtype) was performed under the assumption that treprostinil and epoprostenol were clinically equivalent. Two cohorts of 60 patients, treated with treprostinil or epoprostenol, were evaluated over three years by using a dynamic spreadsheet model. The evaluation included both the provincial ministries of health and societal perspectives. Resource valuation data for drugs, medical supplies, consultations, and surgical and diagnostic procedures were obtained from standard lists. Costs of hospitalizations and adverse events were derived from published sources. Additional outpatient costs were considered equivalent and, therefore, were excluded from the analysis. Costs are presented in 2003 Canadian dollars discounted at 3\%. Sensitivity analyses were performed testing all uncertainties in the model.

RESULTS: In the base-case analysis (over three years), treatment with treprostinil resulted in an expected savings of $\$ 2,610,642$ and $\$ 2,781,438$ from the ministries of health and societal perspectives, respectively. On a per-patient level, treatment with treprostinil resulted in an average annual savings of $\$ 14,504$ and $\$ 15,452$, respectively. The greatest savings with treprostinil came from reduced hospitalizations. Multivariate sensitivity analyses estimated cost savings in greater than $99 \%$ of scenarios.

CONCLUSIONS: By initiating and continuing treprostinil treatment over a three-year period, the economic burden associated with PAH may be reduced compared with epoprostenol treatment.

Key Words: Cost-effectiveness; Epoprostenol; Health economics; Pulmonary arterial hypertension; Treprostinil

\section{Rapport coût-efficacité du tréprostinil par rapport à l'époprosténol chez des patients atteints d'hypertension artérielle pulmonaire : analyse de la situation au Canada}

CONTEXTE : L'hypertension artérielle pulmonaire (HTAP) est associée à une morbidité et à une mortalité élevées et elle a une très forte inci dence sur les patients, tant sur le plan économique que sur celui de la santé. La présente étude avait pour but d'établir l'évaluation économique du tréprostinil et de l'époprosténol chez des patients atteints d'HTAP.

MÉTHODE : Nous avons procédé à une analyse de minimisation des coûts (sous-type d'analyse de rentabilité) en supposant que le tréprostinil et l'époprosténol étaient cliniquement équivalents. Deux cohortes de 60 patients traités au tréprostinil et à l'époprosténol ont été évaluées sur une période de trois ans à l'aide d'un modèle dynamique avec tableur. Nous avons tenu compte, dans l'évaluation, des points de vue tant des ministères de la Santé que de la société. Les données sur la valeur des ressources utilisées pour les médicaments, les fournitures médicales, les consultations, les interventions diagnostiques et les interventions chirurgicales ont été obtenues à partir des listes habituelles. Les coûts relatifs aux hospitalisations et aux effets indésirables provenaient de publications. D'autres coûts pour les malades externes ont été jugés équivalents et, par suite, exclus de l'analyse. Les coûts sont exprimés en dollars canadiens de 2003, actualisés à un taux de $3 \%$. Toutes les incertitudes du modèle ont été soumises à des analyses de sensibilité.

RÉSULTATS : Dans l'analyse de base, étalée sur trois ans, le traitement au tréprostinil s'est soldé par des économies prévues de 2610642 \$ pour les ministères de la Santé et de 2781438 \$ pour la société. De plus, le traitement au tréprostinil a permis, sur le plan individuel, des économies annuelles moyennes de 14504 \$ et de 15452 \$ respectivement. Les économies les plus importantes attribuables au tréprostinil s'expliquent par la réduction du nombre d'hospitalisations. Des analyses de sensibilité multifactorielles ont servi à évaluer les économies de coût dans plus de $99 \%$ des scénarios.

CONCLUSION : L'instauration et la poursuite du traitement au tréprostinil sur une période de trois ans, par rapport au traitement à l'époprosténol, permettent une réduction du fardeau économique associé à l'HTAP.
$\mathrm{P}$ ulmonary arterial hypertension (PAH) is a condition of abnormally high pressure within the pulmonary arterial circulation, characterized by an increase in pulmonary vascular resistance and a mean pulmonary artery pressure of $25 \mathrm{mmHg}$ or greater $(1,2)$. No investigations to date have provided definitive data on the incidence, prevalence and mortality of PAH.
However, idiopathic PAH (IPAH), a subtype of PAH, is estimated to have an annual incidence of one to two cases per one million people in both the United States and Europe (3). Based on that rate, an estimated 300 to 600 new cases of IPAH would occur per year in the United States, or 30 to 60 new cases in Canada. Left untreated, IPAH leads to premature death. In

${ }^{1}$ Faculty of Pharmacy, University of Toronto, Toronto; ${ }^{2}$ PharmIdeas Research and Consulting Inc, Oakville; ${ }^{3}$ Toronto General Hospital, Faculty of Medicine, University of Toronto, Toronto; ${ }^{4}$ Faculty of Business, Brock University, St Catharines; ${ }^{5}$ Northern Therapeutics Inc, Toronto, Ontario Correspondence and reprints: Michael Iskedjian, PharmIdeas Research and Consulting Inc, 1175 North Service Road West, Suite 211, Oakville,

Ontario L6M 2W1. Telephone 905-465-3090 ext 223, fax 905-465-3091, e-mail skedji@pharmideas.com 
one study from the United States (4), the mean survival time was 2.8 years, and the five-year survival rate was $34 \%$. Therefore, IPAH is a disease with serious implications.

The treatment of IPAH is aimed at relieving symptoms, improving physical activity and increasing survival (1). Prostacyclins constituted the first therapeutic class of drugs approved by Health Canada for the treatment of severe New York Heart Association (NYHA) functional class III and class IV pulmonary hypertension. Flolan (epoprostenol; GlaxoSmithKline, Canada), the first approved prostacyclin, is indicated for the long-term intravenous treatment of IPAH and secondary pulmonary hypertension due to the scleroderma spectrum of diseases in NYHA functional class III and class IV patients who are not adequately responding to conventional therapy $(5,6)$. Unfortunately, because epoprostenol must be delivered as a continuous intravenous infusion, it may be associated with various severe adverse events such as septicemia and the threat of acute hemodynamic instability from interrupted line flow due to the loss of line integrity (7).

In October 2002, United Therapeutics (USA) received approval from Health Canada to market Remodulin (treprostinil sodium), a new prostacyclin for the long-term, subcutaneous treatment of PAH in NYHA class III and class IV patients who are not adequately responding to conventional therapy (8). Treprostinil is an improvement over previous prostacyclins; it has an increased half-life and has been shown to be an effective treatment when administered via a continuous subcutaneous infusion $(9,10)$. The subcutaneous route of delivery results in fewer serious adverse events than the intravenous route. These serious adverse events include local and systemic infections, thrombosis and paradoxical emboli (11). Furthermore, the subcutaneous route of delivery may improve patient survival compared with conventional therapy (12). Results from a recent clinical trial (13) suggest that three-year patient survival with subcutaneously administered treprostinil is no worse than patient survival with intravenously administered epoprostenol.

The differences between the delivery routes of the two drugs are expected to have an impact on the rate of medical resource utilization required for the clinical management of PAH. In the United States, Highland et al (14) performed a decision analysis examining the cost-effectiveness of bosentan, epoprostenol and treprostinil in treating PAH. The study reported that over a one-year treatment horizon, treatment with bosentan would provide a cost savings compared with both treprostinil and epoprostenol. In addition, based on various assumptions, they reported that treatment with epoprostenol may provide a cost savings compared with treprostinil.

To date, no Canadian study has assessed this difference in terms of an economic evaluation of the two drugs. The present study is the first to examine this issue, and the first to report a pharmacoeconomic evaluation of subcutaneous treprostinil compared with intravenous epoprostenol in the treatment of patients with NYHA class III or IV PAH from the view point of the Canadian health care system.

\section{METHODS}

The primary audience for the present evaluation includes the various Canadian provincial drug benefit plans as payers, physicians as prescribers, and patients as users. The primary analytical perspective was that of the various Canadian provincial ministries of health $(\mathrm{MoH})$. Secondary perspectives included the societal perspective to provide results to the decision makers of the various benefit plans.

A three-year time horizon was chosen for the analysis based on a median survival time of 2.8 years in patients untreated for IPAH (4). This time horizon allowed the capture of all relevant outcomes in the decision model. The model incorporated the dosetitration phase in addition to maintenance therapy.

In accordance with the Canadian and Ontario guidelines for economic evaluations of pharmaceuticals, the pharmacotherapy being evaluated was compared with the existing practice (ie, the most prevalent clinical practice, and either the lowest cost comparator or the 'do-nothing' approach) $(15,16)$. In the case of treprostinil, the most appropriate comparator was epoprostenol. Due to the severe nature of the disease, the do-nothing approach was not considered appropriate.

\section{Model design}

The analyses were conducted by using a decision analytical spreadsheet model based in Microsoft Excel (Microsoft Corporation, USA). The economic model used was a cost-minimization analysis. This model was adopted as a result of preliminary data analysis, expert clinical opinion, and results from noncomparative studies indicating that both treprostinil and the comparator, epoprostenol, provide an effect significantly greater than placebo. In addition, based on the results of a recent three-year clinical trial (13), the two drugs provide equal survival in patients with severe PAH.

An incidence-based model was used to follow both treprostinil and epoprostenol treatment in two cohorts of 60 patients with PAH in NYHA class III and class IV. Each patient underwent a dose-titration phase in addition to maintenance therapy, as determined by specialists experienced in managing such cases. The spreadsheet model was designed to represent the logical sequence of clinical practice as described in the literature. All points were verified by expert clinical opinion.

\section{Resource utilization}

Parameter values for the analyses were primarily determined from the published literature. Resource utilization data were derived from clinical trials and published treatment guidelines. Expert clinical opinion was used to confirm the resource utilization data extracted and to provide guidance in areas of uncertainty requiring further sensitivity analyses.

Drug costs were determined from standard lists wherever available (eg, the Ontario Drug Benefits Formulary or the Régie de l'assurance ,aladie du Québec) (17-19). The unit cost of treprostinil was provided by the manufacturer as a provisional cost within a plausible range; this range was applied to sensitivity analyses. Treprostinil is administered through a continuous subcutaneous infusion and, for the present analysis, was dosed based on a $0.82: 1$ ratio versus epoprostenol (20). The average dose used in the base-case analysis was $22.2 \mathrm{ng} / \mathrm{kg} / \mathrm{min}$ (daily dose of $2.24 \mathrm{mg}$ ). The unit cost of treprostinil used was $\$ 45.00 / \mathrm{mg}$. Because treprostinil is initiated as an outpatient therapy in the majority of cases, the dose is titrated over a period of two to 12 weeks to reach a therapeutic dose level based on the patient's response and ability to tolerate titration. The inpatient daily dose cost used was $\$ 100.08$ because the delivery system was a multidose vial without any drug wastage.

Epoprostenol is administered by intravenous infusion and usually requires hospitalization for a period of five to 10 days to titrate the drug to a maintenance level and to ensure enough time for the patient to receive proper training on how to reconstitute the drug and how to appropriately care for the drug delivery system. Treatment is 
normally initiated at $2 \mathrm{ng} / \mathrm{kg} / \mathrm{min}$ to $4 \mathrm{ng} / \mathrm{kg} / \mathrm{min}$ with a target dose of $10 \mathrm{ng} / \mathrm{kg} / \mathrm{min}$ to $15 \mathrm{ng} / \mathrm{kg} / \mathrm{min}$ in two to four weeks (21). The mean dose for adults is approximately $20 \mathrm{ng} / \mathrm{kg} / \mathrm{min}$ to $40 \mathrm{ng} / \mathrm{kg} / \mathrm{min}$ (22). In the present analysis, the mean weight of a patient was estimated to be $70 \mathrm{~kg}$ and the mean dose was $27.2 \mathrm{ng} / \mathrm{kg} / \mathrm{min}$ (daily dose of $2.72 \mathrm{mg}$ ) (20). The inpatient daily dose cost of epoprostenol was $\$ 83.49$ (Table 1).

Daily medication costs were determined based on the number of units required for each daily dose. In-hospital medication costs did not include any additional dispensing fees. However, outpatient medication costs included a $\$ 6.54$ dispensing fee for each prescription and a $10 \%$ markup on the cost of the drug, less a $\$ 2.00$ copayment. These drug costing approaches were used for both treprostinil and epoprostenol.

Medical consultation fees were derived from the Ontario Schedule of Benefits for Physician Services (18). All patients incurred the cost of an initial consultation with their family practitioner and the cost of referral to a specialist, regardless of the treatment. Experts were consulted to establish the type and frequency of visits that patients would require for each drug. For both treatments, a team of specialists, including a cardiologist, rheumatologist and a respiratory disease specialist, initially examined each patient. Although patients should be seen by the entire consulting team on a monthly basis, it was assumed that some patients would be unable to make monthly visits. As a result, it was estimated that $50 \%$ of patients would adhere to the monthly visits and $50 \%$ would make bimonthly visits. Because clinical practice may differ dramatically among practitioners, and some may only follow-up on a patient every three months or longer, it was preferable to be conservative and err toward a higher frequency of visits.

In addition to visits for specialist consultations, medical visits included the nurse's time to train the patients. Before discharging patients whose drug dose was being titrated, both the patient and a spouse or close relative received training from a specially trained nurse on proper catheter care, sterile techniques and drug preparation and administration.

Costs of surgical and diagnostic procedures were derived from the Schedule of Benefits for Physician Services and other standard price reference lists such as the Ontario Schedule of Benefits for Laboratory Services $(5,17)$. Epoprostenol requires the surgical placement of an intravenous catheter (treprostinil does not require such a procedure); thus, in the model, all patients treated with epoprostenol incurred the cost of having this procedure performed. Total costs of other diagnostic procedures were based on the frequency of performing each assessment and the proportion of patients who required the procedure, with data being derived from the literature $(2,23)$. Utilization rates were verified by expert clinical opinion.

Hospitalization rates and utilization were determined from the literature $(2,24)$. Each listed reference presented data from several sources. Costs varied slightly according to the source; however, the valuations were similar among all reported resources.

Epoprostenol use, because of its route of infusion, puts patients at risk for sepsis and line infections (5). McLaughlin et al (7) reported a $14 \%$ rate of sepsis for epoprostenol treatment. For this reason, the present study also sought to determine the cost of treating sepsis. The costs of treating other adverse events associated with treprostinil or epoprostenol were considered comparable or minor; hence, they were not considered in the present analysis. For example, the cost to manage injection site pain in treprostinil patients was not included. However, injection site pain is presumably managed by outpatient treatment, and it was not expected to substantially affect the results of the analysis.
TABLE 1

Medication resource utilization by patients with pulmonary arterial hypertension

\begin{tabular}{lll}
\hline Resource & \multicolumn{1}{c}{ Utilization* $^{*}$} & Valuation (\$) \\
\hline Medication & & \\
Treprostinil $^{\dagger}$ & $22 \mathrm{ng} / \mathrm{kg} / \mathrm{min}^{\ddagger}$ & $45.00 / \mathrm{mg}$ \\
Epoprostenol$^{\S}$ & $27 \mathrm{ng} / \mathrm{kg} / \mathrm{min}$ & $23.33 / \mathrm{mg}$ \\
Drug diluent $^{\S}$ & $50 \mathrm{~mL} / \mathrm{vial}$ & $10.00 / \mathrm{vial}$
\end{tabular}

\begin{tabular}{|c|c|c|}
\hline \multicolumn{3}{|l|}{ Infusion pump and supplies } \\
\hline Treprostinil ${ }^{\dagger}$ & $100 \%$ & $21.00 / \mathrm{d}$ \\
\hline Epoprosteno|§ & $100 \%$ & $44.00 / d$ \\
\hline \multicolumn{3}{|l|}{ Physician visits $\pi$} \\
\hline General physician & Yearly & 54.75 \\
\hline \multicolumn{3}{|l|}{$\begin{array}{c}\text { Cardiologist, rheumatologist, } \\
\text { and respiratory specialist }\end{array}$} \\
\hline Consultation & Yearly & 125.00 \\
\hline \multirow[t]{2}{*}{ Subsequent visits } & $50 \%$ - monthly & 24.65 \\
\hline & $50 \%$ - bimonthly & \\
\hline \multirow[t]{2}{*}{ Training nurse $e^{* *}$} & Treprostinil - 1 session & $30.00 / d$ \\
\hline & Epoprostenol - 5 sessions & \\
\hline \multicolumn{3}{|l|}{ Diagnostic procedures ${ }^{\dagger \dagger}$} \\
\hline Echocardiogram & Every 6 months & 12.55 \\
\hline Right heart catheterization & Every 6 months & 151.10 \\
\hline Pulmonary angiogram & Every 6 months & 107.50 \\
\hline Exercise stress test & Every 6 months & 107.80 \\
\hline Chest radiography & Yearly & 39.50 \\
\hline Thorax CT & Yearly & 65.60 \\
\hline \multicolumn{3}{|l|}{ Oxygen consumption studies } \\
\hline Simple spirometry & Every 6 months & 16.80 \\
\hline Lung compliance & Every 6 months & 99.95 \\
\hline Blood-gas analysis & Every 6 months & 11.45 \\
\hline Oxygen saturation & Every 6 months & 4.25 \\
\hline Blood cultures - CBC & Yearly & 7.76 \\
\hline \multicolumn{3}{|l|}{ Surgical procedures } \\
\hline \multirow[t]{2}{*}{ 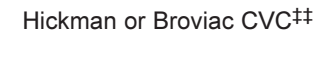 } & $0 \%$ - treprostinil & 132.85 \\
\hline & Yearly - epoprostenol & \\
\hline \multirow[t]{2}{*}{ Removal of CVC } & $0 \%$ - treprostinil & 38.70 \\
\hline & Yearly - epoprostenol & \\
\hline
\end{tabular}

*Data from references 2 and 23 (all points were verified by expert clinical opinion); †The source of valuation was the manufacturer; ${ }^{\ddagger} D a t a$ from reference 20; §Data from reference 19; "Data from reference 5; ${ }^{* *}$ Data from reference 26; ${ }^{+t} D$ ata from references 5 and 17; $¥$ Manufactured by Bard Access Systems, USA. CBC Complete blood count; CT Computed tomography; CVC Central venous catheter

\section{RESOURCE VALUATION}

Resource utilization and the unit costs of medications, delivery systems, consultations and laboratory and diagnostic procedures are presented in Table 1. For epoprostenol, the unit cost per milligram was determined to be $\$ 23.33$ (19). However, the daily medication cost of epoprostenol also included the cost of the diluent used to prepare the medication. The cost per vial of diluent required for the constitution of Flolan was $\$ 10.00$ (19). Coverage rates for both the drug delivery system and required infusion supplies were determined to be $\$ 21$ per day and $\$ 44$ per day for treprostinil and epoprostenol, respectively. The utilization rates for procedures and diagnostics derived from expert opinion were lower than the frequency suggested in the guidelines. However, variations in utilization rates were equal in both arms. Thus, any bias introduced would have been the same for both treatment arms. The time spent 
TABLE 2

Extent of hospitalization by treatment type

\begin{tabular}{lcc}
\hline & \multicolumn{2}{c}{ Treatment } \\
\cline { 2 - 3 } Hospitalization & Treprostinil & Epoprostenol \\
\hline $\begin{array}{l}\text { Length of stay for dose- } \\
\text { titration phase }\end{array}$ & $\begin{array}{c}0 \text { days }- \text { dose titration } \\
\text { (performed as outpatient) }\end{array}$ & 10.5 days \\
$\begin{array}{c}\text { Length of stay for } \\
\text { rehospitalizations }\end{array}$ & 10.2 days & 15 days \\
$\begin{array}{l}\text { Probability per year of } \\
\text { rehospitalizations }\end{array}$ & 0.68 admissions/year & 1.0 admission/year \\
& &
\end{tabular}

*Utilization rates were determined from a presentation on resource use in Canadian pulmonary arterial hypertension patients treated with epoprostenol (24) and verified by expert clinical opinion; ${ }^{\dagger}$ Data derived from reference 25 ; $\neq D$ ata derived from the epoprostenol rate minus the adverse event rates associated with the epoprostenol drug delivery system (eg, sepsis and loss of line integrity) (24)

on training patients was determined to be a single 15 min session for treprostinil and five daily $15 \mathrm{~min}$ sessions for epoprostenol.

To determine the total cost of hospitalization, the average length of stay (ALOS) in the hospital was multiplied by the average daily hospital cost. The ALOS reported in the literature for epoprostenol treatment was 15 days per rehospitalization for NYHA class III and class IV patients, and was confirmed by expert clinical opinion (25). A summary of the utilization of hospital resources is presented in Table 2. To standardize the published hospital costs $(26,27)$ from previous years into 2003 Canadian dollars, published dollar values were adjusted by using the health portion of the consumer price index (28). Hospital costs used in the model are presented in Table 3. For the dose-titration phase of epoprostenol treatment, the hospitalization cost was determined by multiplying the length of stay for titration by the cost per day of being in an intensive care unit (ICU). For rehospitalization costs of both therapies, the average hospitalization cost per day was determined in the following manner:

$$
\begin{gathered}
(1 \text { day } \times \text { emergency room cost }+[\text { ALOS }-1] \times 0.50 \times \text { ICU per day } \\
+[\text { ALOS }-1] \times 0.50 \times \text { general ward per day }) / \text { ALOS }
\end{gathered}
$$

where ALOS is rehospitalization average length of stay. The rehospitalization ALOS for treprostinil (10.2 days) was determined by multiplying the ALOS for epoprostenol (15 days) by the probability of rehospitalization for treprostinil (0.68). The weighting of 0.50 for ICU time and for general ward time was based on clinical expertise.

Resource use per septic episode was determined from the literature (29) and was presented as the mean cost per episode. The estimated cost per episode, in 2003 Canadian dollars, was $\$ 16,228$, from Letarte et al (29).

\section{Sensitivity analyses}

Various assumptions were used to facilitate the analysis. Each assumption was determined by either a literature review or from expert clinical opinion. The uncertainty inherent in each assumption was tested by sensitivity analyses, except for the assumption that the frequency of patient consultations was equally distributed in both comparators. Because this assumption did not introduce any bias, it was not expected to influence the results.

Multivariate sensitivity analyses were performed by using Monte Carlo simulations to determine the robustness of our model to probability distributions for each uncertain parameter. The simulations were conducted by using 10,000 iterations for each analysis. The results of each analysis are presented as the mean value of the results generated from the 10,000 iterations.
TABLE 3

\begin{tabular}{|c|c|c|c|c|}
\hline Parameter & $\begin{array}{c}\text { Cost/value } \\
\text { (\$) }\end{array}$ & Year & $\begin{array}{l}\text { CPI adjusted } \\
(\$)^{\star}\end{array}$ & $\begin{array}{c}\text { Study } \\
\text { (reference) }\end{array}$ \\
\hline Cost per ICU day & 1572.00 & 1992-2003 & 1950.89 & Norris et al (27) \\
\hline $\begin{array}{l}\text { Cost per general } \\
\text { ward day }\end{array}$ & 612.00 & 1995-2003 & 709.31 & IHE (26) \\
\hline Emergency room & $390.00^{\dagger}$ & NA & $390.00^{\dagger}$ & SoB (18) \\
\hline
\end{tabular}

Hospitalization valuations and required adjustments

*Adjusted to 2003 valuation by using the health care portion of the consumer price index (CPI); tIncludes a physician consultation and ambulance trip patient copayment. ICU Intensive care unit; IHE Institute of Health Economics; NA Not available; SoB Schedule of Benefits for Physician Services

\section{RESULTS}

Base-case and sensitivity parameters, including the probability distributions used in the multivariate analyses, are presented in Table 4 . The unit price of treprostinil was $\$ 45 / \mathrm{mg}$ for all basecase analyses and the dose adjustment factor was maintained at 0.82:1 (ratio of treprostinil to epoprostenol). Table 5 presents the total expected costs of each therapy categorized by resource type. The highest contributor to the total cost of treprostinil therapy was the per milligram unit cost of the drug. The unit cost constitutes approximately $64 \%$ of the total valuation of resources consumed during treprostinil therapy.

Treprostinil was expected to be cost saving in the first month, first year and over the three-year period, with expected savings to the $\mathrm{MoH}$ of $\$ 1,317,317, \$ 1,773,474$ and $\$ 2,610,642$, respectively. The average per-person, per-day costs over the three years were $\$ 135$ and $\$ 175$ for treprostinil and epoprostenol, respectively, from the $\mathrm{MoH}$ perspective. Hence, the per-patient incremental cost saving with treprostinil treatment was approximately $\$ 40$ per day. Hospitalizations accounted for approximately $34 \%$ of the total cost of epoprostenol treatment over three years but contributed nearly $43 \%$ to the total cost in the first year, mostly as a result of the ALOS required to titrate the drug dose to an effective maintenance level.

The majority of the cost savings resulted from the difference between the hospital resource use of the treprostinil cohort and the hospital resource use of the epoprostenol cohort (Table 5). Over the three-year period, the expected total hospitalization cost was nearly three times greater in the epoprostenol cohort than in the treprostinil cohort.

\section{Sensitivity analyses}

One-way sensitivity analyses were performed to determine the impact of varying specific parameters. The sensitivity of the model to the dose adjustment factor was tested by varying the dose ratio while maintaining all other variables constant. The cost savings of treprostinil were expected to be reduced as the dose ratio approached 1.09:1. Results of the sensitivity analyses are shown in Table 6. A threshold analysis was also performed to determine the dose ratios at which point there would be no more savings with treprostinil. The break even point was determined at a dose ratio of 1.48:1 at one year and 1.20:1 at three years.

Multivariate analyses were performed from both the $\mathrm{MoH}$ and societal perspectives. The probability of cost savings with treprostinil versus epoprostenol treatment was $100 \%$ in the first year and greater than $99 \%$ over three years from both the $\mathrm{MoH}$ and societal perspectives. Results of the multivariate analyses are presented in Table 7 . The results indicate robustness against alterations in all important parameters across all plausible ranges. 
TABLE 4

Parameter values tested in the multivariate sensitivity analyses

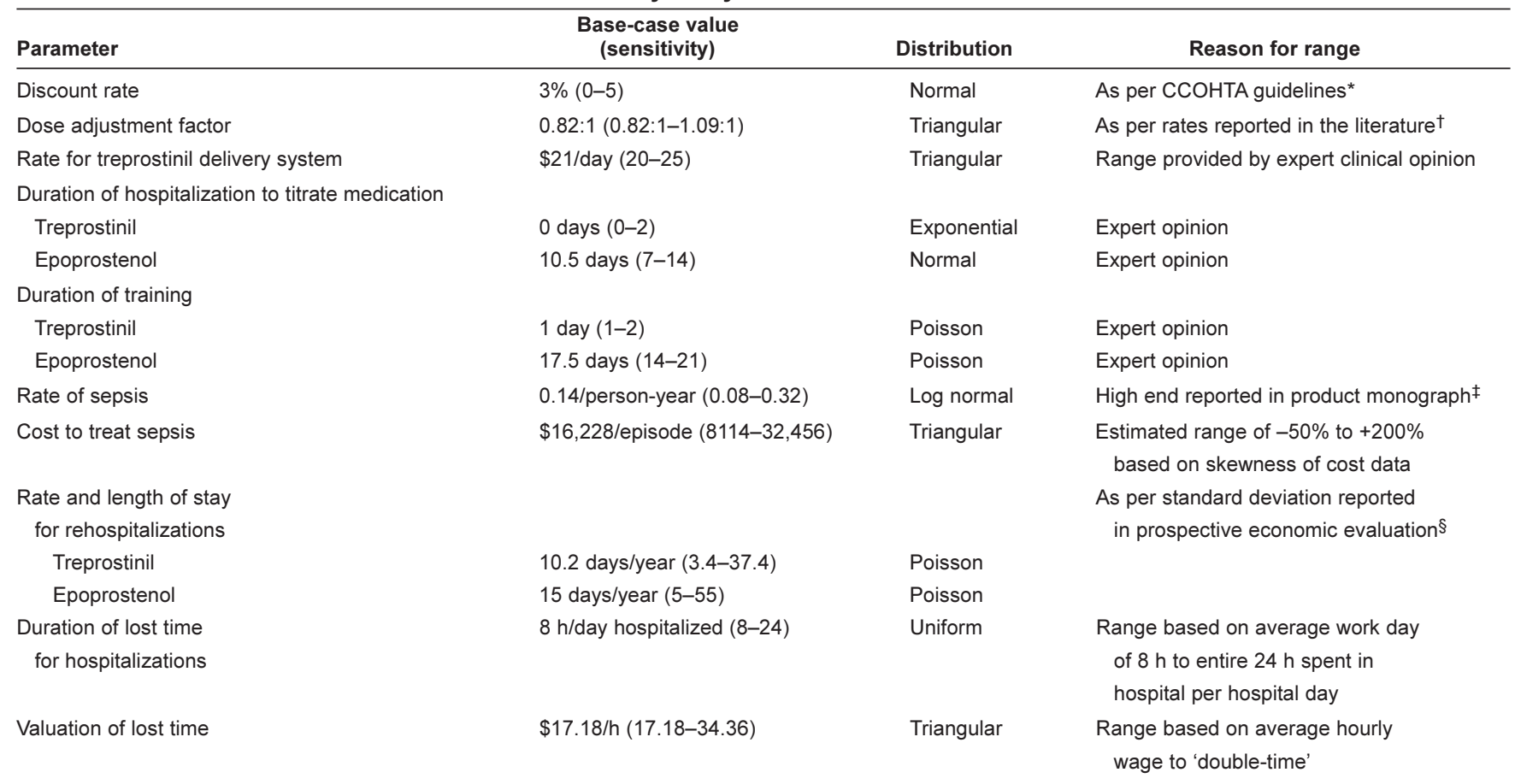

${ }^{*}$ Data from reference $16 ;{ }^{\dagger}$ Data from references 20 and 30 ; ${ }^{\ddagger}$ Data from reference 5 ; ${ }^{\S}$ Data from reference 25. CCOHTA Canadian Coordinating Office for Health Technology Assessment

TABLE 5

Itemized costs of each therapy

\begin{tabular}{|c|c|c|c|c|c|c|}
\hline \multirow[b]{2}{*}{ Item } & \multicolumn{3}{|c|}{ Treprostinil (\$) } & \multicolumn{3}{|c|}{ Epoprostenol (\$) } \\
\hline & 1 month & 1 year & 3 years & 1 month & 1 year & 3 years \\
\hline \multicolumn{7}{|l|}{ Cohort } \\
\hline Drug and cost & 202,985 & $2,234,806$ & $5,666,759$ & 162,923 & $1,847,786$ & $4,693,427$ \\
\hline Equipment & 38,351 & 422,236 & $1,070,657$ & 80,355 & 884,685 & $2,243,281$ \\
\hline Medical visits & 28,463 & 68,844 & 98,694 & 69,341 & 112,590 & 142,440 \\
\hline Procedures & 37,455 & 64,367 & 160,372 & 45,426 & 74,112 & 184,620 \\
\hline Hospitalization & 120,211 & 770,092 & $1,870,521$ & $1,375,377$ & $2,289,579$ & $3,896,749$ \\
\hline$A E-$ sepsis & 0 & 0 & 0 & 11,360 & 125,066 & 317,127 \\
\hline Total MoH cost & 427,465 & $3,560,345$ & $8,867,003$ & $1,744,782$ & $5,333,819$ & $11,477,645$ \\
\hline Lost time & 11,181 & 81,708 & 201,039 & 96,895 & 197,553 & 371,835 \\
\hline Total SOC cost & 438,646 & $3,642,053$ & $9,068,042$ & $1,841,677$ & $5,531,372$ & $11,849,480$ \\
\hline
\end{tabular}

AE Adverse events; MoH Ministry of health perspective; SOC Societal perspective

\section{DISCUSSION}

The present economic evaluation was performed to provide the decision makers of various drug plans with a pharmacoeconomic profile of treprostinil in the treatment of patients with severe PAH (NYHA class III or IV). In the base-case analysis, the first three years of treating the cohort with treprostinil resulted in a cost savings of $\$ 2,610,642$ and $\$ 2,781,438$ from the $\mathrm{MoH}$ and societal perspectives, respectively. On an individual basis, the per-patient incremental cost savings were $\$ 43,511$ and $\$ 43,357$ from the $\mathrm{MoH}$ and societal perspectives, respectively. Thus, treprostinil appears to be cost saving compared with epoprostenol. The key variables for the savings were the hospitalization associated with the titration of epoprostenol and the adverse events associated with the epoprostenol drug delivery system.
To examine the impact of varying the values of key model parameters, a number of one-way sensitivity analyses were performed. The model results were sensitive to scenarios including varying the dose adjustment ratio. In the majority of cases, most of the model results were congruent in magnitude with the cost savings found from the base-case analysis. The Monte Carlo simulations predicted results similar to what was determined through one-way sensitivity analyses. Cost savings after the third year of treatment were favourable for treprostinil, with cost savings in more than $99 \%$ of simulations from both the $\mathrm{MoH}$ and societal perspectives.

No other Canadian economic evaluation of treprostinil has been published. An American study by Highland et al (14) reported results that were inconsistent with our findings. 


\section{TABLE 6}

Base-case savings* and sensitivity results from both the provincial ministries of health (MoH) and societal perspectives

\begin{tabular}{lcc}
\hline & \multicolumn{1}{c}{ MoH (\$) } & Societal (\$) \\
\cline { 2 - 3 } Scenario & $2,610,642$ & $2,781,438$ \\
\hline Base-case savings & $2,726,857$ to $2,538,346$ & $2,905,264$ to $2,704,407$ \\
Discount rate, $0 \%$ to $5 \%$ & $2,610,642$ to 747,191 & $2,781,438$ to 917,987 \\
Dose adjustment ratio, $0.82: 1$ to $1.09: 1$ & $2,311,259$ to $3,508,788$ & $2,464,789$ to $3,731,383$ \\
Sepsis rate, 0.08 to 0.32 events per person-year & $2,452,078$ to $2,927,769$ & $2,622,874$ to $3,098,565$ \\
Average cost per episode of sepsis, $\$ 8114$ to $\$ 32,456$ & & $2,781,438$ to $2,491,904$ \\
ALOS during dose titration & $2,610,642$ to $2,337,120$ & $2,353,917$ to $3,208,958$ \\
$\quad$ Treprostinil, 0 to 2 days & $2,211,143$ to $3,010,140$ & \\
$\quad$ Epoprostenol, 7 to 14 days & & $2,781,438$ to $2,779,690$ \\
Duration of training days & $2,610,242$ to $2,608,894$ & $2,775,321$ to $2,787,554$ \\
$\quad$ Treprostinil, 1 to 2 days & $2,604,525$ to $2,616,758$ & $2,832,421$ to $2,577,503$ \\
Epoprostenol, 14 to 21 days & $2,621,625$ to $2,406,707$ & $2,138,163$ to $5,354,536$ \\
Daily drug system coverage rate, $\$ 20$ to $\$ 25$ & $2,027,856$ to $4,941,783$ & $2,781,438$ to $3,131,036$ \\
ALOS for rehospitalizations per year, 5 to 55 days & NA & $2,781,438$ to $2,952,234$ \\
Utilization of lost time, $8 \mathrm{~h}$ to $24 \mathrm{~h}$ & $\mathrm{NA}$ & \\
Valuation of lost time, $\$ 17.18$ to $\$ 34.36$ per hour &
\end{tabular}

*Savings are presented as cumulative values. ALOS Average length of stay; NA Not applicable

TABLE 7

Results of Monte Carlo simulations from both the provincial ministries of health (MoH) and societal perspectives

\begin{tabular}{|c|c|c|c|c|c|c|}
\hline \multirow[b]{2}{*}{ Incremental savings } & \multicolumn{2}{|c|}{ Month 1} & \multicolumn{2}{|c|}{ Year 1} & \multicolumn{2}{|c|}{ Year 3} \\
\hline & MoH (\$) & Societal (\$) & MoH (\$) & Societal (\$) & MoH (\$) & Societal (\$) \\
\hline Mean & 824,447 & 977,837 & $1,072,887$ & $1,314,759$ & $1,536,089$ & $1,934,517$ \\
\hline $\mathrm{SD}$ & 119,281 & 162,604 & 236,865 & 285,720 & 538,259 & 603,800 \\
\hline Median & 828,198 & 972,883 & $1,084,992$ & $1,315,654$ & $1,577,265$ & $1,955,270$ \\
\hline Probability of savings, $\%$ & 100 & 100 & 100 & 100 & $>99$ & $>99$ \\
\hline
\end{tabular}

However, various limitations were present in that study, such as the assumption of equal hospital resource utilization between the two therapies and the use of average doses that are out of line with current dose studies (20). In addition, the decision analysis performed did not include the cost to treat sepsis, as indicated in both the product monograph and recent epoprostenol studies $(5,7)$.

Although no comparable Canadian cost-effectiveness study was available, an unpublished cost analysis of epoprostenol in 27 Canadian patients with PAH did report a trend in epoprostenol resource valuation that was similar to that in our study (24). The average cost per day of epoprostenol treatment, including the direct and indirect costs reported in that study, was $\$ 211$ (2001 Canadian dollars). In the present analysis, we concluded that the average cost per day of epoprostenol was $\$ 135$ from the $\mathrm{MoH}$ perspective and $\$ 175$ from the societal perspective. As a result, our economic evaluation produced conservative expected costs of epoprostenol compared with the previous prospective cost analysis; however, determining the cost of that treatment with treprostinil would still result in a cost savings of $\$ 40$ to $\$ 42$ per day from the $\mathrm{MoH}$ perspective to the societal perspective.

As with any economic analysis, certain limitations were inherent in the present evaluation. As noted in the Methods section, a conservative approach was used for estimating the frequency of follow-up visits in the analysis. Significant variability may exist among treatment centres and that may in turn have an impact, to a certain extent, on the results of the analysis. Although a higher frequency may introduce a bias against epoprostenol, one may argue, on the other hand, that from a quality of life perspective, fewer visits may be expected with treprostinil. Furthermore, the relative impact of the frequency of follow-up visits would not change the overall direction of the results. Additionally, the base-case analysis did not include the cost of pain management for each treatment. The actual cost of pain management could not be captured accurately and, therefore, it did not seem sensible to include the assumption in our base-case analysis, especially from the $\mathrm{MoH}$ perspective.

\section{CONCLUSIONS}

Although treprostinil and epoprostenol have shown comparable clinical efficacy, they are administered by different delivery systems. The treprostinil delivery system has been associated with an improved safety profile compared with epoprostenol. As a result, the economic profile of treprostinil was expected to be more resource efficient than that of epoprostenol.

As our results suggest, based on a cost-minimization analysis, treprostinil is a more resource efficient treatment, providing a cost savings over epoprostenol of $\$ 43,511$ per patient over a three-year period. The greatest cost savings were attributed to a decrease in the ALOS during dose titration and fewer 
hospitalizations due to adverse events associated with the route of administration and the epoprostenol delivery system.

The evidence provided by the present pharmacoeconomic evaluation suggests that using treprostinil to treat patients with PAH could provide cost savings from both the $\mathrm{MoH}$ and societal perspectives over a three-year period. The average saving per day was estimated to be $\$ 40$ to $\$ 42$ per patient.

ACKNOWLEDGEMENTS: Funding for this study was provided by Northern Therapeutics Inc, Toronto, Ontario. Northern Therapeutics distributes treprostinil in Canada. Northern Therapeutics provided costing data and helped to design the study. John T Granton, Toronto General Hospital, Toronto, Ontario, provided clinical expertise in this study. Colin Vicente works at Wyeth Pharmaceuticals, Markham, Ontario.

\section{REFERENCES}

1. Pass SE, Dusing ML. Current and emerging therapy for primary pulmonary hypertension. Ann Pharmacother 2002;36:1414-23

2. British Cardiac Society Guidelines and Medical Practice Committee, and approved by the British Thoracic Society and the British Society of Rheumatology. Recommendations on the management of pulmonary hypertension in clinical practice. Heart 2001;86(Suppl 1):I1-13.

3. Gaine SP, Rubin LJ. Primary pulmonary hypertension. Lancet 1998;352:719-25. (Erratum in 1999;353:74).

4. D'Alonzo GE, Barst RJ, Ayres SM, et al. Survival in patients with primary pulmonary hypertension. Results from a national prospective registry. Ann Intern Med 1991;115:343-9.

5. Canadian Pharmacists Association. Compendium of Pharmaceuticals and Specialties: The Canadian Drug Reference for Health Professionals. Toronto: Webcom Limited, 2003.

6. Health Canada - Health Products and Food Branch. Notices of Compliance: Prescription pharmaceuticals for human use, 1997. <http://www.hc-sc.gc.ca/dhp-mps/alt_formats/hpfb-dgpsa/txt/ prodpharma/pre97et_e.txt> (Version current at November 10, 2005).

7. McLaughlin VV, Shillington A, Rich S. Survival in primary pulmonary hypertension: The impact of epoprostenol therapy. Circulation 2002;106:1477-82.

8. Health Canada - Health Products and Food Branch. Notices of Compliance: Prescription pharmaceuticals for human use, 2002. <http://www.hc-sc.gc.ca/dhp-mps/alt_formats/hpfb-dgpsa/txt/ prodpharma/pre2002et.txt> (Version current at November 10, 2005).

9. Simonneau G, Barst RJ, Galie N, et al; Treprostinil Study Group. Continuous subcutaneous infusion of treprostinil, a prostacyclin analogue, in patients with pulmonary arterial hypertension: A double-blind, randomized, placebo-controlled trial. Am J Respir Crit Care Med 2002;165:800-4.

10. McLaughlin V. Improvement in exercise tolerance with treprostinil is dose related for pulmonary arterial hypertension. The American Thoracic Society 2002 International Conference. Atlanta, Georgia, May 20 to 23, 2002.
11. McLaughlin VV, Gaine SP, Barst RJ, et al; Treprostinil Study Group. Efficacy and safety of treprostinil: An epoprostenol analog for primary pulmonary hypertension. J Cardiovasc Pharmacol 2003;41:293-9.

12. Gibbs JS, Arneson CP, Mottola C. Chronic infusion of treprostinil is safe, and appears to prolong survival over a three-year period in patients with pulmonary arterial hypertension. Circulation 2002;106(Suppl II):575. (Abst)

13. Vachiery J, Naeije R. Treprostinil for pulmonary hypertension. Expert Rev Cardiovasc Ther 2004;2:183-91.

14. Highland KB, Strange C, Mazur J, Simpson KN. Treatment of pulmonary arterial hypertension: A preliminary decision analysis. Chest 2003; 124:2087-92.

15. Ontario Ministry of Health and Long-Term Care. Ontario Guidelines for Economic Analysis of Pharmaceutical Products. Toronto: Institutional Services Branch, Ministry of Health, 1994.

16. Canadian Coordinating Office for Health Technology Assessment. Guidelines for Economic Evaluation of Pharmaceuticals: Canada, 2nd edn. Ottawa: CCOHTA,1997.

17. Ontario Ministry of Health. Schedule of Benefits: Laboratory Services under the Health Insurance Act. Toronto: Institutional Services Branch of the Ministry of Health, 1999.

18. Ontario Ministry of Health. Schedule of Benefits: Physician Services under the Health Insurance Act. Toronto: Institutional Services Branch of the Ministry of Health, 2003.

19. Régie de l'assurance maladie du Québec. Liste des Médicaments. Québec: RAMQ, 2003.

20. Vachiery JL, Hill N, Zwicke D, Barst R, Blackburn S, Naeije R. Transitioning from iv epoprostenol to subcutaneous treprostinil in pulmonary arterial hypertension. Chest 2002;121:1561-5.

21. Galie N, Manes A, Branzi A. Medical therapy of pulmonary hypertension. The prostacyclins. Clin Chest Med 2001;22:529-37.

22. Widlitz A, Barst RJ. Pulmonary arterial hypertension in children. Eur Respir J 2003;21:155-76.

23. Schulman K, Glick H, Buxton M, et al. The economic evaluation of the FIRST study: Design of a prospective analysis alongside a multinational phase III clinical trial. Flolan International Randomized Survival Trial. Control Clin Trials 1996;17:304-15.

24. Banayan D, Witt J, McCarthy M, Granton JT. The direct and indirect costs of chronic intravenous epoprostenol in patients with pulmonary arterial hypertension. American Thoracic Society 99th International Conference. Seattle, Washington, May 16, 2003.

25. Schulman KA, Buxton M, Glick H. Results of the economic evaluation of the first study. A multinational prospective economic evaluation. FIRST Investigators. Flolan International Randomized Survival Trial. Int J Tech Assess Health Care 1996;12:698-713.

26. Alberta Institute for Health Economics. Hospital per diem costs. Edmonton: Institute for Health Economics, 2000.

27. Norris C, Jacobs P, Rapoport J, Hamilton S. ICU and non-ICU cost per day. Can J Anaesth 1995;42:192-6.

28. Statistics Canada. Consumer Price Index - Health Care. CANSIM II - v735519 Table 326-0001. Ottawa: Statistics Canada, 2003.

29. Letarte J, Longo CJ, Pelletier J, Nabonne B, Fisher HN. Patient characteristics and costs of severe sepsis and septic shock in Quebec. J Crit Care 2002;17:39-49.

30. Treprostinil (Remodulin) for pulmonary arterial hypertension. Med Lett Drugs Ther 2002;44:80-2. 


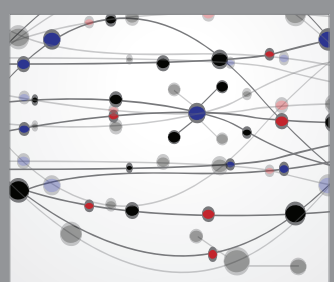

The Scientific World Journal
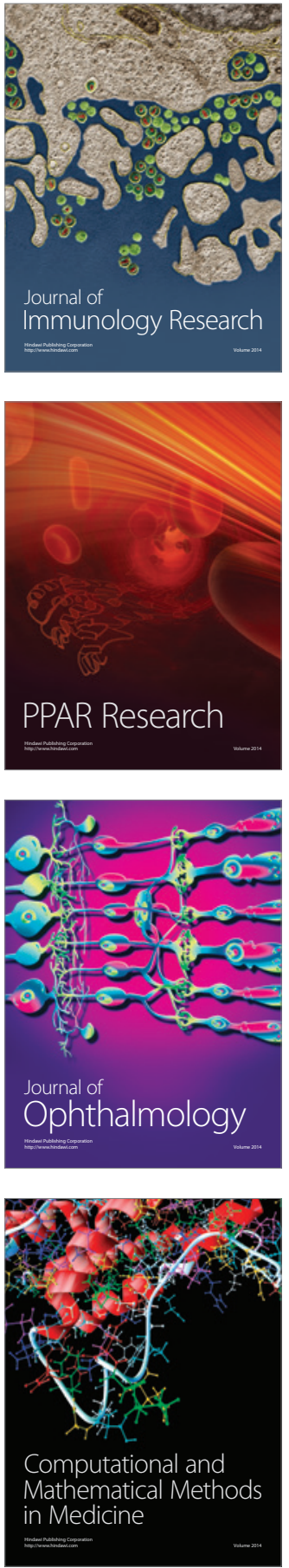

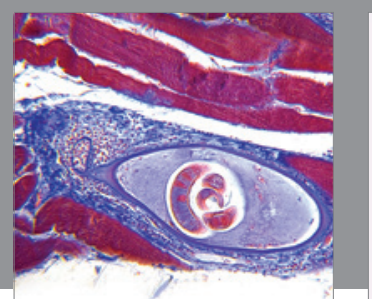

Gastroenterology Research and Practice

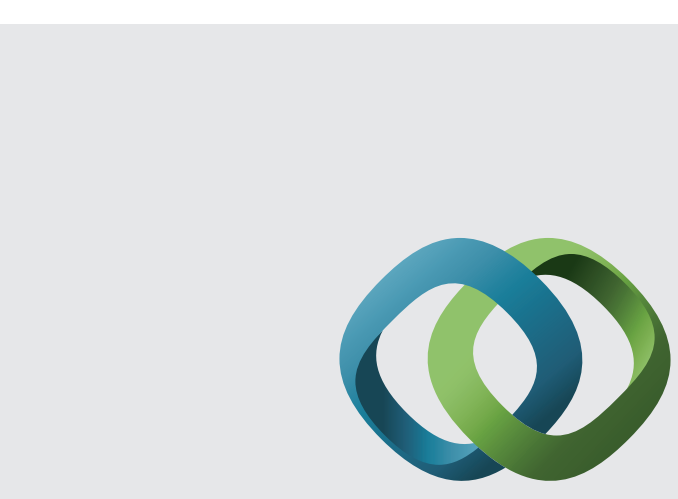

\section{Hindawi}

Submit your manuscripts at

http://www.hindawi.com
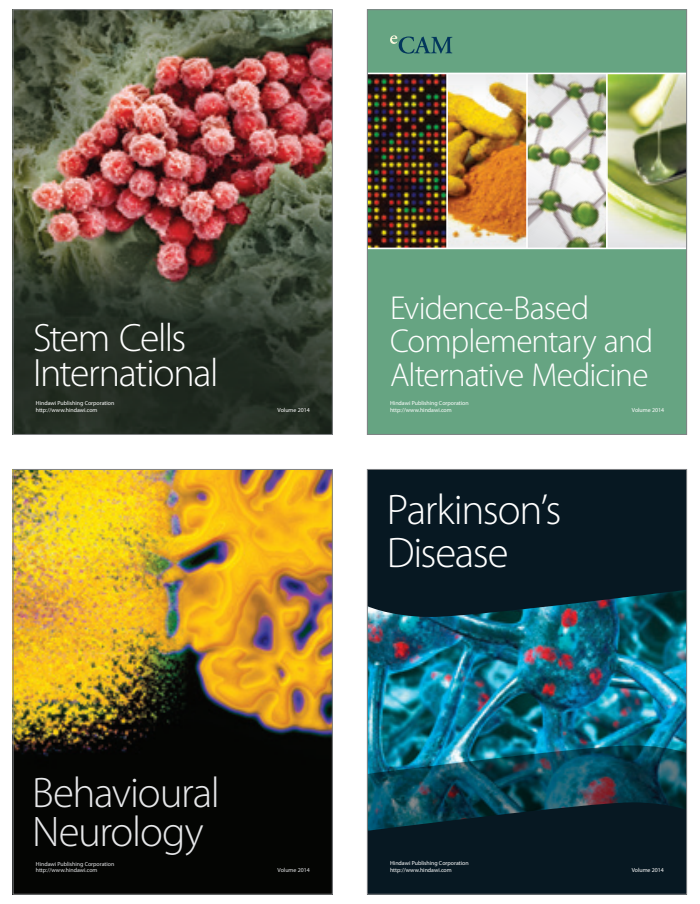
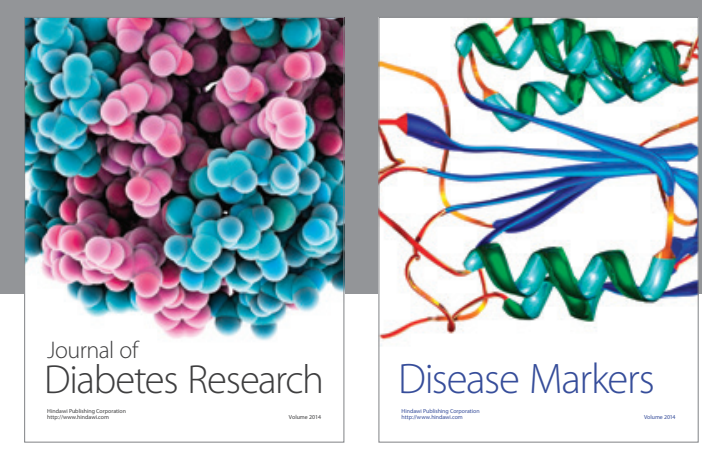

Disease Markers
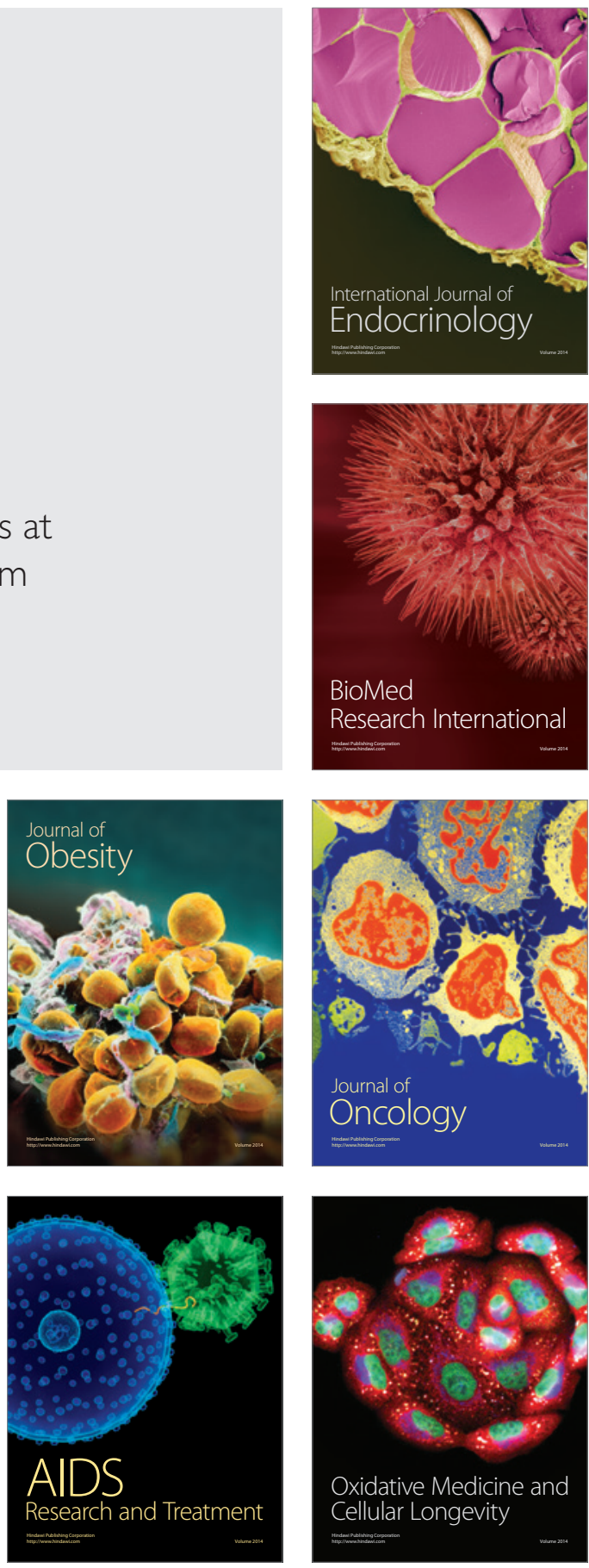